\title{
Relation between Proper Management, Feedback Frequency and Employee Age
}

\author{
Saulius Olencevicius \\ ISM University of Management and Economics \\ Mogens Dilling-Hansen \\ Aarhus BSS, Aarhus University
}

Research suggests that effective feedback intervention must be frequent (Kuvaas, Buch, \& Dysvik, 2016; Lam, DeRue, Karam, \& Hollenbeck, 2011; Salmoni, Schmidt, \& Walter, 1984). In the present study, the dependency of psychologically perceived proper management is analysed with respect to satisfaction of feedback frequency and different age groups of employees in a Central and Eastern European (CEE) country. The empirical study is based on survey data from 1,405 employees in a large Lithuanian manufacturing entity. Results shows that perceived proper management is highly related to employee satisfaction and feedback intervention frequency, but a clear relation to the employee age is not found.

\section{INTRODUCTION}

Employee feedback satisfaction plays an important role in individual performance, work satisfaction, and organizational engagement (Anseel, Van Yperen, Janssen, \& Duyck, 2011; Kluger \& DeNisi, 1996; Kuvaas et al., 2016). Every individual has his/her own perception regarding feedback frequency and how it is related to perceived proper management style. Therefore, different age individuals see feedback intervention process differently (Aguinis, Gottfredson, \& Joo, 2012; Dysvik, Kuvaas, \& Gagne, 2013; Qian et al., 2016). Historical research on feedback frequency does not fully disclose its impact on perceived individual satisfaction, attitude to management, and work performance (Kuvaas \& Buch, 2016; Kuvaas et al., 2016). The aging of employees plays an important role in organizational climate and performance (Truss, Ahantz, Soane, Alfes, \& Delbridge, 2013; Zacher, Heusner, Schmitz, Zwierzanska, \& Frese, 2010), and therefore, it needs to be addressed thoroughly.

In the present study, the authors conceptualize general perception of feedback frequency by using different feedback signs such as positive, neutral or negative. Feedback delivery and employees age, as separate constructs, have received the attention of growing managers and researchers (Goštautaite \& Bučiūnienè, 2015; Kluger \& DeNisi, 1998). However, most research is performed in Western Europe, Asia and the US, thus lacking higher focus on the Central and Eastern European (CEE) region (Brewster, Morley, \& Bučiūnienè, 2010).

Post-Soviet countries are a unique region. Thus, through fifty years of the Soviet period, an imprint on management and feedback delivery style is exhibited. During that period, managers have treated feedback more as a control tool, rather than a motivational support option, and organizations have relied 
on authority as a primary managerial tool (Sears \& Tamulionyte-Lentz, 2000). The CEE region is not well researched and documented (Brewster et al., 2010). Therefore, this study is conducted in Lithuania and focuses on employees of different age groups and their perception of feedback delivery frequency, and it supports the scientific discussion about the CEE region. The study provides information whether individuals are satisfied with feedback intervention frequency, and whether they see it as a proper management factor.

The aim of this paper is to provide a theoretical background and supportive empirical evidences of the satisfaction level of employees in different age groups with feedback intervention frequency and correlation to perceived proper management style. Proper management is defined as a general principle and the understanding of modern leadership (motivation vs. punishment) or classical Confucianism, which has existed for more than 2,500 years. Confucianism sets a standard for humanity, respect, moralism and ethos for interpersonal relationships (Ames \& Hershock, 2018; Low \& Ang, 2013), and according to Liu (2015), Confucianism could be important in present human resource globalization processes. During a lifespan, individuals are demonstrating a positive learning curve based on practical knowledge and experience, so aging persons disclose higher level of moralism, wisdom, and understanding of managerial essence. Therefore, acknowledgement of basic Confucianism values in a lifespan could have a potential positive effect on satisfaction with management and feedback frequency (Ames \& Hershock, 2018).

This study contributes to research in the feedback intervention area in several ways. Firstly, by measuring perceived proper management and comparing it to satisfaction with feedback frequency, one can predict how employees of different ages evaluate their line managers. Therefore, it is possible to estimate how proper management depends on employee satisfaction with feedback frequency. Secondly, the individual reactions to feedback frequency from different age groups are measured. This allows evaluation of the attitude of employees of different ages towards the same demonstrated frequency of feedback intervention.

\section{THEORY AND HYPOTHESES}

\section{Proper Management}

Perceived proper management in this study is conceptualized as the generally perceived satisfaction with line managers and their management style, which can be related to doctrines of Confucianism and modern leadership interpretations. Despite that Confucian attitude is still not widely spread among CEE companies, employees quite frequently intrinsically put effort into following the Confucian rules or principles.

Confucianism, whose fundamental principle is humanism, is considered a proper human relationship and basis of society (Liu, 2015; Yum, 2009), learning, positive management and harmonious relationships (Low \& Ang, 2013). The priority is dedicated to warm human behaviour among employees, where social and interpersonal relationships are oriented to receiver-centred communication (Yum, 2009). Confucian daily management activities are focusing on team spirit, harmony, trustworthiness, and transparency (Low \& Ang, 2013). Therefore, employees feel they are more respected and important, which leads to satisfaction with the perceived proper management. Since the individual reflections on satisfaction in general are based on experience and experience increases with age, the first hypothesis raised is that perceived satisfaction depends on age:

Hypothesis 1: Perceived proper management positively relates to the age of the employee: the more mature behaviour the employee exhibits, the higher the level of satisfaction with the management.

Traditionally, managers have been older and more experienced comparing to their subordinates, and as such, they are perceived more wise and competent (Staudinger \& Gluck, 2011). Due to demographic changes and the aging workforce challenges, today's managers can be relatively younger than their subordinates (Collins, Hair, \& Rocco, 2009). Therefore, a team members are more focused on 
interpersonal relationships and perceived proper management per se, where the management is more like an act of supervision and refers to skills of executive ability (Low \& Ang, 2013).

However, the authors acknowledge that in modern daily business relationships, people are more focused on the leadership context. This can be defined as the nature of the influencing process and relationship between leader and follower (Antonakis, 2004) or interpersonal influence of individual and group (French, Rayner, Rees, \& Rumbles, 2008). In the present study, different leadership styles are not differentiated, as this is not in the scope of this research, and is used in corpore - from low-quality transactional relationships to high-quality socio-emotional relationships (Kuvaas \& Buch, 2016).

\section{Feedback Frequency}

In the present paper, feedback intervention is defined as actions taken by (an) external agent(s) to provide information regarding some aspect(s) of one's task performance (Kluger \& DeNisi, 1996). Feedback, positive and negative, can lead to individual performance and behaviour changes (Anseel et al., 2011; Kluger \& Van-Dijk, 2005; Van-Dijk \& Kluger, 2011). Therefore, in human resource practice, it is considered an important organizational stimulus (Lam et al., 2011; Sijbom, Anseel, Crommelinck, De Beuckelaer, \& De Stobbeleir, 2017). Perceived feedback frequency is conceptualized as a multiple dimension of individual subordinate attitude and evaluation regarding supervisor actions, received comments about performance of daily tasks, and learning.

The majority of the feedback studies demonstrate positive feedback frequency's influence on recipient satisfaction, performance, motivation, and learning (Bouskila-Yam \& Kluger, 2011; Dysvik et al., 2013; Kluger \& Van-Dijk, 2005; Kuvaas et al., 2016; Luque \& Sommer, 2000; Sommer \& Kulkarni, 2012; Van-Dijk \& Kluger, 2004), but some studies show interesting contradictory results, where the excess of feedback frequency ends up in decreasing performance and learning (Lam et al., 2011). However, the absence of feedback in general may lead people to dissatisfaction and even demotivation on the workplace (Gagne \& Deci, 2005; Moss \& Sanchez, 2004), as intrinsic motivation is not supported. Lower perceived satisfaction with feedback could be influenced by the negative emotions of received criticism, negative feedback (Jawahar, 2010), supervisors mentioned development needs, low performance evaluation, and lower feedback accuracy (Kuvaas et al., 2016).

On the other hand, a non-negative effect on satisfaction from a more regular feedback (positive and negative) is more likely, when individual performance should increase as corrective actions are more frequent, and feedback interpretation is carried out more on the self-level, instead of on the task-level (Kluger \& DeNisi, 1996). Perceived satisfaction with frequent feedback is more related to the positive emotions and well-being, whereas dissatisfaction is related to negative emotions and well-being (Kuvaas, 2011; Sparr \& Sonnentag, 2008).

However, heavy supervisorial workload and personal attitude towards the feedback process is not promising such desired frequency (Harms \& Roebuck, 2010). Therefore, the perceived satisfaction with feedback frequency is still uncertain, as some employees demonstrate feedback seeking behaviour and some feedback avoiding behaviour (Moss \& Sanchez, 2004; Tuckey, Brewer, \& Williamson, 2002). This means that both types (feedback seeking and feedback avoiding) of individuals can be satisfied with different levels and context of feedback interventions. Therefore, the authors propose that perceived satisfaction with feedback frequency is a more general psychological construct involving multiple related dimensions.

Increased feedback frequency requires an increase in recipients processing cognitive resources. This may shift attention from the task to the self, and therefore, performance improvement and learning may be reduced (Lam et al., 2011). However, when individuals gain experience, cognitive resources will not be overloaded, and employees will handle negative aspects of frequent feedback more easily (Lam et al., 2011). This could explain the higher level of satisfaction with frequent feedback of older individuals, as older employees demonstrate a higher level of gained knowledge and experience (Ardelt, 2004).

Theory predict a relation between proper management and feedback frequency, and in this analysis, the positive effect is expected to dominate a potential negative effect, leading to the following hypothesis: 
Hypothesis 2: Perceived proper management depends on satisfaction with feedback frequency: the higher the level of feedback satisfaction, the higher the level of satisfaction with management.

International human resource management literature is currently engaged in the debate related to existing cultural and institutional differences (Brewster, 2004; Brewster et al., 2010), such as organizational autonomy, exposure to market processes, the role of group versus individual, trade union, and state interference (Sparrow \& Hiltrop, 1997). The CEE region, where personnel management function played more political and administrative role than motivational (Lucas, Marinova, Kucerova, \& Vetrokova, 2011), is still in a transformation process. Therefore, cultural differences need to be researched in more detail. The present study discloses aspects of such differences.

\section{Experience and age}

According to the theoretical section, the experience of the employees will affect the overall satisfaction, but measuring experience in practice is not easy. Age is used as the proxy in the present study. It is defined as chronological age in years (Kooij, de Lange, Jansen, \& Dikkers, 2013) and grouped in intervals of five years periods. Age usually distinguishes young employees from older, where term "older" may involve individuals already age 40 or more (De Lange et al., 2010).

Following theories on lifespan development and self-regulation, researchers identifying two directions of human resource practices: development (e.g., training) and maintenance (feedback, performance appraisal) (Kooij, Guest, et al., 2013). Based on research, well-being (job satisfaction, organizational commitment) weakens with age, if organizations focus on development practices and strengthens, if maintaining practices are in place (De Lange et al., 2010; Kooij, Guest, et al., 2013). The literature suggests that maintaining practices support a positive relationship between feedback and employee age, but there is still no clear information regarding the influence of feedback frequency. Accordingly, the next hypothesis is raised:

Hypothesis 3: Employee age is positively related to perceived satisfaction with feedback frequency: the older the age group, the higher the satisfaction.

However, performance feedback shows vague effects in aging research, where older employees do not benefit from feedback (Ellis, Palmer, \& Reeves, 1988; Rebok \& Balcerak, 1989). At the same time, some studies suggest that objective and negative feedback can result in disengagement in older individuals, where goals alone or positive feedback can improve their performance and satisfaction (Locke \& Latham, 2013).

\section{METHOD}

\section{Procedure and Sample}

The data used in this research was a part of a wider digital employee survey. To provide honest and valid answers, respondents participated anonymously in the online-distributed questionnaire. The employees are all working in the same firm. Due to confidentiality, the name of the company is not revealed, but it is a traditional manufacturing CEE company, operating since Soviet times.

After detailed review and validation of the collected data, responses from 1,405 respondents were used for the further analysis. The sample consists of 399 (28.4\%) female and 1,006 (71.6\%) male participants. Their working experience is solid, as a majority of them $(81.4 \%)$ have been actively working eleven and more years. $11.3 \%$ of the respondents had up to five years of organizational tenure, and $7.3 \%$ had a period of six to ten years of organizational tenure. Age estimation was aggregated into the following groups by focusing on eight five-year periods: $21-25$ years old $(0.6 \%), 26-30$ years old $(2.8 \%), 31-35$ years old $(5.1 \%), 36-40$ years old $(7.4 \%), 41-45$ years old $(8.5 \%), 46-50$ years old $(8.7 \%), 51-55$ years old (26.1\%), and 56 years and older (40.7\%). The data shows that the employees are quite mature and have solid professional experience. 


\section{Measures}

In the present study, the following measures were used as proxies for perceived proper management, perceived regular feedback from direct supervisor, and age.

Perceived proper management of direct supervisor was evaluated using a 6-point Likert scale. Each participant was asked to provide his or her score of the statement: "My direct supervisor properly manages employees". Response options ranged from 1 ('Totally disagree') to 6 ('Totally agree'). "Don't know" is not used. By following best practices, 5- or 7- point scales were not used in order to avoid an uninformative "middle" score that does not give any specific value to the researcher and instead contaminating the data (Baumgartner \& Steenkamp, 2001). Besides, it allows to the respondents to avoid honest, but unpleasant, answers by delivering a "politically correct" evaluation, which is still popular in Lithuania. Therefore, to avoid such data contamination, the scale was made of 6-points.

Perceived feedback frequency from a direct supervisor was measured using a 6-point Likert scale too. Each participant was asked to provide his or her score of the statement: "My direct supervisor provides me a regular feedback about my achievements". Response options ranged from 1 ('Totally disagree') to 6 ('Totally agree'), and arguments for not using 5- or 7-point Likert scale are the same as presented in the previous paragraph.

$\boldsymbol{A g} \boldsymbol{e}$ was measured on an ordinal scale by asking respondents to mark the chronological / calendar age group they belong to. Respondents self-reported their dependence to one of the eight denominated age groups, which were split in five-year intervals, and the midpoints of the intervals were used as age of the employees.

\section{RESULTS}

Descriptive data are presented below in Table 1. The data was generated as a total cross-section sample of the population of employees in a major traditional CEE/Lithuanian company, and after check of data, the net samples consist of 1,405 (valid observations) employees. The population of employees is 1,675, and with 102 non-responses, 104 not-completed responses, and 64 deleted observations (answers were not valid), the net response rate is $83.9 \%$. Top management is not included, and management is defined as the closest line manager.

TABLE 1

DESCRIPTIVE STATISTICS

\begin{tabular}{lccccc}
\hline Variables & $\boldsymbol{N}$ & Minimum & Maximum & Mean & $\begin{array}{c}\text { Std. } \\
\text { Deviation }\end{array}$ \\
\hline Perceived proper management & 1,405 & 1 & 6 & 5.03 & 1.08 \\
Regular feedback & 1,405 & 1 & 6 & 4.55 & 1.39 \\
Gender - male share & 1,405 & 0 & 1 & 0.72 & 0.45 \\
Job tenure in company & 1,405 & 1 & 3 & 2.70 & 0.66 \\
White blue collars - share & 1,405 & 0 & 1 & 0.53 & 0.50 \\
Dummy Young (le 35 years) & 1,405 & 0 & 1 & .085 & 0.28 \\
Dummy Tenure & 1,405 & 0 & 1 & .814 & 0.39 \\
Age & 1,405 & 23 & 60 & 51.54 & 9.43 \\
Valid N & 1,405 & & & & \\
\hline
\end{tabular}

Notes: Age is grouped in 5-year intervals in order to maintain confidentiality. Job tenure is also grouped due to confidentiality.

The company is characterized by a majority of male employees and a very low turnover rate: average age is above 50 years, and only $8.5 \%$ are younger than 35 years. The distribution of the dependent variable perceived proper management, and the view on regular feedback are both left-skewed. 
According to hypothesis 1 and 3, perceived proper management and perceived satisfaction with feedback are positively related to age. Figure 1 shows the relation between the two Likert-scaled variables on age and perceived satisfaction with management and feedback. In both cases, a weak positive relation is found supporting the expected outcome.

In hypothesis 1, a positive relation between perceived proper management and age was expected, and the estimated linear model in Figure 1 (right) supports the hypothesis. Hypothesis 3 proposes a positive relation between satisfaction with feedback frequency and age, and the estimated linear model (left) also supports the expected relation. However, in both cases, only a weak positive effect is found, and especially the 31-35 age group expresses a lower satisfaction than expected. These findings are aligned with the expectations in an organization with many employees with high seniority; the satisfaction is high in the beginning of a long career in the company ("employees do what they are told to do"), followed by a period of high involvement and interest in changing the firm ("employers want to innovate the firm"), and after a number of years, the overall acceptance of how the firm is managed increases ("employees accept their role in the company").

\section{FIGURE 1 \\ PERCEIVED SATISFACTION WITH PROPER MANAGEMENT / FEEDBACK FREQUENCY AND AGE}
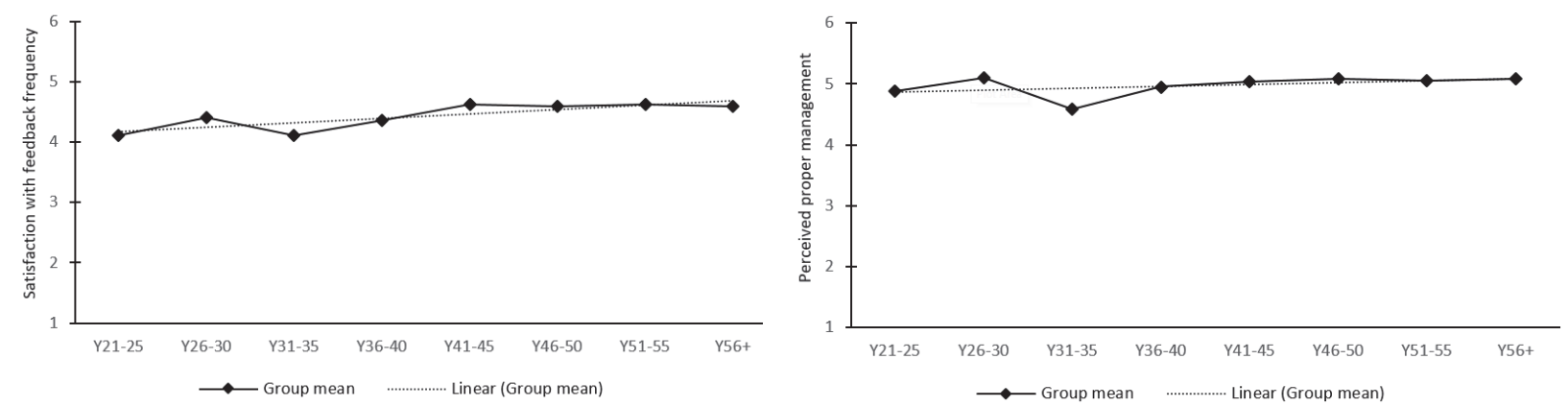

Notes: Using an $\alpha$-level of $5 \%$, the linear model left (satisfaction with feedback frequency) is significant (P-value $1.2 \%$ ), and the linear model right (proper management) is also significant (P-value $2.3 \%$ ). Only $3 \%$ of the samples are aged below 30 years; results are unaffected by exclusions of these observations.

Table 2 shows the empirical analysis explaining the perceived proper management using feedback frequency and age as explanatory variables. The methodology used in the analysis is standard linear regression using dummies for gender and various measures of age, and the potential interaction effect between control variables and perception of regular feedback is calculated using the dummy version of age and gender. Only significant results are shown in Table 2 below. 
TABLE 2

PERCEIVED PROPER MANAGEMENT DETERMINANTS

\begin{tabular}{|c|c|c|c|c|c|c|}
\hline Explanatory variables & $\begin{array}{c}\text { Model 1 } \\
\text { Basic }\end{array}$ & $\begin{array}{c}\text { Model } 2 \\
\text { Age }\end{array}$ & $\begin{array}{c}\text { Model 3 } \\
\text { Age } \\
\text { dummy }\end{array}$ & $\begin{array}{c}\text { Model } 4 \\
\text { Full } \\
\text { model }\end{array}$ & $\begin{array}{c}\text { Model 5 }^{2} \\
\text { Blue- } \\
\text { collar }\end{array}$ & $\begin{array}{c}\text { Model } 6^{3} \\
\text { White- } \\
\text { collar }\end{array}$ \\
\hline Intercept & $\begin{array}{c}3.217 * * \\
(0.084)\end{array}$ & $\begin{array}{c}3.068^{* *} \\
(0.155)\end{array}$ & $\begin{array}{l}3.236^{* *} \\
(0.086)\end{array}$ & $\begin{array}{c}3.291 * * \\
(0.090)\end{array}$ & $\begin{array}{c}3.578 * * \\
(0.126)\end{array}$ & $\begin{array}{c}2.957 * * \\
(0.127)\end{array}$ \\
\hline Regular feedback & $\begin{array}{c}0.399 * * \\
(0.018)\end{array}$ & $\begin{array}{c}0.398 * * \\
(0.018)\end{array}$ & $\begin{array}{c}0.398^{* *} \\
(0.018)\end{array}$ & $\begin{array}{c}0.386^{* *} \\
(0.019)\end{array}$ & $\begin{array}{c}0.332 * * \\
(0.026)\end{array}$ & $\begin{array}{c}0.451^{* *} \\
(0.027)\end{array}$ \\
\hline Age & & $\begin{array}{c}0.003 \\
(0.003)\end{array}$ & & & & \\
\hline Young $^{1}$ & & & $\begin{array}{c}-0.126 \\
(0.088)\end{array}$ & $\begin{array}{c}-0.619^{*} \\
(0.264)\end{array}$ & $\begin{array}{c}-1.113 * * \\
(0.400)\end{array}$ & $\begin{array}{l}-0.090 \\
(0.347)\end{array}$ \\
\hline Regular feedback* Young & & & & $\begin{array}{l}0.116^{*} \\
(0.059)\end{array}$ & $\begin{array}{c}0.228 * * \\
(0.087)\end{array}$ & $\begin{array}{c}-0.007 \\
(0.079)\end{array}$ \\
\hline $\mathbf{P}(\mathbf{F})$ & 0.000 & 0.000 & 0.000 & 0.000 & 0.000 & 0.009 \\
\hline $\mathbf{R}^{2}$-adjusted & 0.264 & 0.265 & 0.265 & 0.267 & 0.220 & 0.323 \\
\hline $\mathbf{N}$ & 1,405 & 1,405 & 1,405 & 1,405 & 746 & 659 \\
\hline
\end{tabular}

The expected positive relation between regular feedback and perceived proper management formulated in hypothesis 2 is clearly supported in the analysis presented in Table 2 (Model 1), where the positive and significant result is robust in all specifications of the model.

According to hypothesis 1, a positive relation between proper management and age is expected, but after having controlled for satisfaction with feedback frequency, there is not found any direct relation between the two dimensions. There is only a weak and insignificant positive relation between age and perceived proper management, regardless of the specification of age, and all specifications of age are not significant at a $10 \%$ confidence level. Model 2 and 3 illustrate the weak positive relation of the dependent variable and age.

The direct effect of age is in general weak, and therefore a potential interaction between age and satisfaction with regular feedback is tested in the last two models. The argument is that young employees with low level of "on-the-job-training" need feedback more than employees with knowledge about daily routines. The dummy variable for young employees captures all employees aged 35 or below, and Model 4 shows that there is a generally lower satisfaction among young employees (coefficient for dummy variable "Young" is negative), but despite this negative effect, there is also an extra positive effect from feedback. There is a significant lower satisfaction among younger employees, but they appreciate feedback, because feedback is helpful for understanding how the firm operates.

There are few job types and gender specific effects found in the analysis, but the interaction effect between age and satisfaction with feedback frequency is an interesting exception. Table 3 shows that job type and gender is highly interdependent, because the majority of blue-collar workers are men (600 male; 534 was expected), whereas women are overrepresented in the white-collar group (253 female; only 187 was expected). Gender has no direct effect on satisfaction (males are marginally more satisfied), and job type has only a weak effect since blue-collar employees are slightly more satisfied than white-collar employees.

Model 5 in Table 2 is based only on blue-collar employees, and the estimation is in line with the full Model 4, except for higher significance. Estimating the interaction model only on the white-collar subsample (Model 6 in Table 2), the changes in the results are very clear and without a significant interaction 
effects. Model 6 is the full model including interaction effects, but only estimated on the 659 white-collar employees, and the model confirms the very robust and significant positive relation between satisfaction with the management team and the feedback frequency. However, there is no longer any age effect, and the positive interaction effect between age and feedback is also insignificant. When estimating the model only on the female sub-samples, similar results were found (not presented), but the basic differences are job-type based.

TABLE 3

JOB TYPE AND GENDER

\begin{tabular}{lccc}
\hline Job type / Gender & Females & Males & Sum \\
\hline Blue-collar & $146(212)$ & $600(534)$ & 746 \\
White-collar & $253(187)$ & $406(472)$ & 659 \\
\hline Sum & 399 & 1,006 & 1,405 \\
\hline
\end{tabular}

Notes: Numbers in brackets are expected numbers given independency between job and gender. A Chi-2 test for independency is highly significant: P-value $<0.0001$.

Based on the differences between Models 4-6, it is concluded that feedback frequency (hypothesis 2) is very important, age (hypothesis 1 ) has only a minor effect, and the interaction between frequency and age (hypothesis 3 ) is only significant when analysing blue-collar employees' perception of satisfaction with the management team.

\section{DISCUSSION}

Feedback intervention research is generally performed using experimental studies in a controlled environment. This study contributes by using real world data from a manufacturing company in a CEE country: Lithuania.

The existing theory clearly indicates that feedback and feedback frequency are important functions in an organizational environment (Anseel et al., 2011; Kluger \& DeNisi, 1996; Kluger \& Van-Dijk, 2005; Kuvaas, 2011; Kuvaas et al., 2016; Lam et al., 2011; Sijbom et al., 2017; Van-Dijk \& Kluger, 2011) and in learning processes (Cavanaugh, 2013; Goodman, Wood, \& Chen, 2011). This paper is based on data from a firm in a CEE region and confirms this very robust and positive relation. Therefore, organizations in the CEE region are making an effort to improve feedback intervention processes to make them more acceptable and recognized among employees. Post-Soviet countries have more limited experience with motivational aspects of feedback delivery than Western countries (Brewster et al., 2010; Sears \& Tamulionyte-Lentz, 2000). Therefore, this study provides a useful guideline, stating that perceived feedback frequency is highly valuable and has a direct impact on employee satisfaction with proper management style.

Analysis show that potential effects on satisfaction from differences in age are weak. The analysis finds a higher level of satisfaction among mature employees, but also suggests that it is only younger employees, who expect feedback. This paper contributes to the literature by introducing an interaction term between age and satisfaction with feedback frequency, and the results show that, on top of the general positive effect from feedback frequency, the younger employees appreciate feedback to a higher degree than older employees. The intuitive explanation is that young employees need feedback to establish job experience.

It is also interesting that the interaction effect is only relevant for manual workers in the sample. Whether this lack of interaction is due to gender issues or job type, needs to be evaluated in future research. 


\section{Theoretical and Practical Implications}

The intention of this paper is to measure age moderated perceived employee satisfaction with management style, and how it depends on feedback intervention frequency. This study indicates that it is important for the managers to use frequent feedback to support their subordinates, and that employees appreciate their efforts in this field.

All individuals have different needs for feedback, whether they are demonstrating feedback-seeking or feedback-avoiding behaviour (Anseel, Beatty, Shen, Lievens, \& Sackett, 2015; Moss \& Sanchez, 2004; Moss, Sanchez, Brumbaugh, \& Borkowski, 2009; Sijbom et al., 2017). The data utilized in this study indicates that employee age group is directly related to perceived satisfaction with feedback frequency; that is, the older employee, the higher the satisfaction. As the results show, more frequent feedback is important for younger individuals, who need a higher level of supervision, support, and learning. Older employees have more experience with the "old kind" of feedback. Therefore, the present level of frequency for them seems to be sufficient.

Another study contribution is that the authors disclosed the directionality relation between perceived proper management and perceived regular feedback. A positive correlation indicates that if employees are satisfied with the amount of feedback, they are willing to treat it as a factor of proper management or leadership. Such valuable communication strengthens the human relationships in the team and supports Confucianism and modern leadership ideology. Managers are responsible for the development of such mutually reciprocal beneficial relationships, where feedback frequency will be optimal, sufficient (Lam et al., 2011), and targeted to the age of the employees.

The objective of the paper was to analyse the relation between the age of the employees and proper management in a CEE context. It was hypothesized that aging individuals will accept and treat their managers more appropriately compared to their young colleagues. However, this assumption was not supported by the data. It means that perceived proper management is not a scope of age-related construct for all job types, and that the effect is mediated by the feedback frequency.

\section{Strengths, Limitations and Future Research Directions}

One of the strengths of the present study is the real-life data with a solid sample size and a high response rate from one company. It helps to disclose an in-depth analysis of different levels of employees, rather than scattered responses from different entities.

The study has an extra methodological strength by implementing different models to disclose perceived proper management determinants. It helps to measure perceived satisfaction with feedback and age influence on proper management in a CEE context, where the majority of studies are done in a Western European or US context.

The existing theories on feedback predict a positive relation between satisfaction with management and feedback frequency. This study is based on information from a traditional manufacturing firm operating in a CEE context, and the results support the theory. The mainstream theory also predicts an age-dependency, but there is only found weak evidence for this relation. Young employees are in general marginally less satisfied but testing for a potential interaction effect reveals that only young blue-collar employees appreciate extra feedback.

In the present study, perceived proper management and perceived feedback frequency was measured on a general psychological assumption, where the respondent attitude was based on self-reported data. To reduce bias in the data, it is suggested to use a higher number of specific questions (scales) that disclose reliability and allow for more precise evaluation of constructs. Future research should focus on the causal structure of gender and job type.

In conclusion, this study demonstrates that satisfaction with proper management depend on open and moral bilateral relationship, whereas the age of individuals only implies a weak positive learning curve for managerial comprehension. Such results reflect values and basic principles of Confucianism, disclosing that intrinsically individuals are seeking to use a human and compassion approach in daily business operations. 


\section{ACKNOWLEDGEMENT}

Thanks to Professor Dr. Alan Charles Freeman for his contribution, constructive feedback, and support.

\section{REFERENCES}

Aguinis, H., Gottfredson, R. K., \& Joo, H. (2012). Delivering effective performance feedback: The strengths-based approach. Business Horizons, 55, 105-111. doi:10.1016/j.bushor.2011.10.004

Ames, R. T., \& Hershock, P. D. (2018). Confucianisms for a changing world cultural order. East-West Center, Honolulu: University of Hawai'i Press.

Anseel, F., Beatty, A. S., Shen, W., Lievens, F., \& Sackett, P. R. (2015). How are we doing after 30 years? A meta-analytic review of the antecedents and outcomes of feedback-seeking behavior. Journal of Management, 41(1), 318-348. doi:10.1177/0149206313484521

Anseel, F., Van Yperen, N. W., Janssen, O., \& Duyck, W. (2011). Feedback type as a moderator of the relationship between achievement goals and feedback reactions. Journal of Occupational and Organizational Psychology, 84, 703-722. doi:10.1348/096317910X516372

Antonakis, J. (2004). The nature of leadership. Thousand Oaks, CA: Sage Publications.

Ardelt, M. (2004). Wisdom as expert knowledge system: a critical review of a contemporary operationalization of an ancient concept. Human Development, 47(5), 257-285. doi:10.1159/000079154

Baumgartner, H., \& Steenkamp, J.-B. E. T. (2001). Response styles in marketing research: a crossnational investigation. Journal of Marketing Research, 38(2), 143-156.

Bouskila-Yam, O., \& Kluger, A. N. (2011). Strength-based performance appraisal and goal setting. Human Resource Management Review, 21(2), 137-147. doi:10.1016/j.hrmr.2010.09.001

Brewster, C. (2004). European perspectives on human resource management. Human Resource Management Review, 14, 365-382. doi:10.1016/j.hrmr.2004.10.001

Brewster, C., Morley, M., \& Bučiūnienè, I. (2010). The reality of human resource management in Central and Eastern Europe. Baltic Journal of Management, 5(2), 145-155. doi:10.1108/17465261011045098

Cavanaugh, B. (2013). Performance Feedback and Teachers' Use of Praise and Opportunities to Respond: A Review of the Literature. Education and Treatment of Children, 36(1), 111-137.

Collins, M. H., Hair, J. J. F., \& Rocco, T. S. (2009). The older-worker-younger-supervisor dyad: A test of the Reverse Pygmalion effect. Human Resource Development Quarterly, 20(1), 21-41. doi:10.1002/hrdq. 20006

De Lange, A. H., Taris, T. W., Jansen, P., Kompier, M. A. J., Houtman, I. L. D., \& Bongers, P. M. (2010). On the relationships among work characteristics and learning-related behavior: Does age matter? Journal of Organizational Behavior, 925-950. doi:10.1002/job.649

Dysvik, A., Kuvaas, B., \& Gagne, M. (2013). An investigation of the unique, synergistic and balanced relationships between basic psychological needs and intrinsic motivation. Journal of Applied Social Psychology, 43, 1050-1064. doi:10.1111/jasp.12068

Ellis, N. R., Palmer, R. L., \& Reeves, C. L. (1988). Developmental and Intellectual Differences in Frequency Processing. Developmental Psychology, 24(1), 38-45.

French, R., Rayner, C., Rees, G., \& Rumbles, S. (2008). Organizational behavior (2 ed.): Chichester, Wiley.

Gagne, M., \& Deci, E. I. (2005). Self-determination theory and work motivation. Journal of Organizational Behavior, 26, 331-362. doi:10.1002/job.322

Goodman, J. S., Wood, R. E., \& Chen, Z. (2011). Feedback specificity, information processing, and transfer of training. Organizational Behavior and Human Decision Processes, 115, 253-267. doi:10.1016/j.obhdp.2011.01.001 
Goštautaitè, B., \& Bučiūnienè, I. (2015). Work engagement during life-span: The role of interaction outside the organization and task significance. Journal of Vocational Behavior, 89, 109-119. doi:10.1016/j.jvb.2015.05.001

Harms, P. L., \& Roebuck, D. B. (2010). Teaching the art and craft of giving and receiving feedback. Business Communication Quarterly, 73(4), 413-431. doi:10.1177/1080569910385565

Jawahar, I. M. (2010). The mediating role of appraisal feedback reactions on the relationship between rater feedback-related behaviors and ratee performance. Group \& Organization Management, 35(4), 494-526. doi:10.1177/1059601110378294

Kluger, A. N., \& DeNisi, A. S. (1996). The effects of feedback interventions on performance: a historical review, a meta-analysis, and a preliminary Feedback Intervention Theory. Psychological Bulletin, 119(2), 254-284. doi:10.1037/0033-2909.119.2.254

Kluger, A. N., \& DeNisi, A. S. (1998). Feedback interventions: Toward the understanding of a doubleedged sword. Current Directions in Psychological Science, 7(3), 67-72. doi:10.1111/14678721.ep10772989

Kluger, A. N., \& Van-Dijk, D. (2005). The interactive effect of feedback sign and task type on motivation and performance. United States Army Research Institute For the Behavioral and Social Sciences.

Kooij, D. T. A. M., de Lange, A. H., Jansen, P. G. W., \& Dikkers, J. S. E. (2013). Beyond chronological age. Examining perceived future time and subjective health as age-related mediators in relation to work-related motivations and well-being. Work \& Stress, 27(1), 88-105. doi:10.1080/02678373.2013.769328

Kooij, D. T. A. M., Guest, D. E., Clinton, M., Knight, T., Jansen, P. G. W., \& Dikkers, J. S. E. (2013). How the impact of HR practices on employee well-being and performance changes with age. Human Resource Management Journal, 23(1), 18-35. doi:10.1111/1748-8583.12000

Kuvaas, B. (2011). The interactive role of performance appraisal reactions and regular feedback. Journal of Managerial Psychology, 26(1-2), 123-137. doi:10.1108/02683941111102164

Kuvaas, B., \& Buch, R. (2016). Leader Self-Efficacy and Role Ambiguity and Follower Leader-Member Exchange. Paper presented at the Academy of Management Annual meeting.

Kuvaas, B., Buch, R., \& Dysvik, A. (2016). Constructive supervisor feedback is not sufficient: Immediacy and frequency is essential. Human Resource Management. doi:10.1001/hrm.21785

Lam, C. F., DeRue, D. S., Karam, E. P., \& Hollenbeck, J. R. (2011). The impact of feedback frequency on learning and task performance: Challenging the "more is better" assumption. Organizational Behavior and Human Decision Processes, 116, 217-228. doi:10.1016/j.obhdp.2011.05.002

Liu, J. (2015). Globalizing Indigenous Psychology: An East Asian Form of Hierarchical Relationalism with Worldwide Implications. Journal for the Theory of Social Behaviour, 45(1), 82-94. doi: $10.1111 /$ jtsb. 12058

Locke, E. A., \& Latham, G. P. (2013). New developments in goal setting and task performance. New York: Routlege.

Low, K. C. P., \& Ang, S.-L. (2013). Management, the Confucian way. Educational Research, 4(2), 8290.

Lucas, R., Marinova, M., Kucerova, J., \& Vetrokova, M. (2011). HRM practice in emerging economies: a long way to go in the Slovak hotel industry. The International Journal of Human Resources Management, 15(7), 1262-1279. doi:10.1080/0958519042000238446

Luque, M. F. S. D., \& Sommer, S. M. (2000). The impact of culture on feedback-seeking behavior: an integrated model and propositions. Academy of Management Review, 25(4), 829-849. doi: $10.2307 / 259209$

Moss, S. E., \& Sanchez, J. I. (2004). Are your employees avoiding you? Managerial strategies for closing the feedback gap. Academy of Management Executive, 18(1), 32-44.

Moss, S. E., Sanchez, J. I., Brumbaugh, A. M., \& Borkowski, N. (2009). The Mediating Role of Feedback Avoidance Behavior in the LMX-Performance Relationship. Group \& Organization Management, 34(6), 645-664. doi:10.1177/1059601109350986 
Qian, J., Han, Z. R., Guo, Z., Yang, F., Wang, H., \& Wang, Q. (2016). The relation of feedback-seeking motives and emotion regulation strategies to front-line managers' feedback source profiles: A person-centered approach. Journal of Management \& Organization, 22(1), 68-79. doi:10.1017/jmo.2015.7

Rebok, G. W., \& Balcerak, L. J. (1989). Memory self-efficacy and performance differences in young and old adults: the effect of mnemonic training. Developmental Psychology, 25(5), 714-721.

Salmoni, A. W., Schmidt, R. A., \& Walter, C. B. (1984). Knowledge of results and motor learning: A review and critical reappraisal. Psychological Bulletin, 95(3), 355-386.

Sears, W. H., \& Tamulionyte-Lentz, A. (2000). Looking for a CEE-specific manager development model. European Business Review, 12(6), 295-307.

Sijbom, R. B. L., Anseel, F., Crommelinck, M., De Beuckelaer, A., \& De Stobbeleir, K. E. M. (2017). Why seeking feedback from diverse sources may not be sufficient for stimulating creativity: The role of performance dynamism and creative time pressure. Journal of Organizational Behavior, 1-14. doi:10.1002/job.2235

Sommer, K. L., \& Kulkarni, M. (2012). Does constructive performance feedback improve citizenship intentions and job satisfaction? The roles of perceived opportunities for advancement, respect, and mood. Human Resource Development Quarterly, 23(2), 177-201. doi:10.1002/hrdq.21132

Sparr, J. L., \& Sonnentag, S. (2008). Feedback environment and well-being at work: the mediating role of personal control and feelings of helplessness. European Journal of Work and Organizational Psychology, 17(3), 388-412. doi:10.1080/13594320802077146

Sparrow, P. R., \& Hiltrop, J.-M. (1997). Redefining the field of European human resource management: a battle between national mindsets and forces of business transition? Human Resource Management, 36(2), 201-219. doi:0090-4848/97/020201-19

Staudinger, U. M., \& Gluck, J. (2011). Psychological wisdom research: commonalities and differences in a growing field. Annual Review of Psychology, 62, 215-241. doi:10.1146/annurev.psych.121208.131659

Truss, C., Ahantz, A., Soane, E., Alfes, K., \& Delbridge, R. (2013). Employee engagement, organizational performance and individual well-being: exploring the evidence, developing the theory. The International Journal of Human Resources Management, 24(14), 2657-2669. doi:10.1080/09585192.2013.798921

Tuckey, M., Brewer, N., \& Williamson, P. (2002). The influence of motives and goal orientation on feedback seeking. Journal of Occupational and Organizational Psychology, 75, 195-216.

Van-Dijk, D., \& Kluger, A. N. (2004). Feedback sign effect on motivation: is it moderated by regulatory focus? Applied Psychology: An International Review, 53(1), 113-135.

Van-Dijk, D., \& Kluger, A. N. (2011). Task type as a moderator of positive/negative feedback effects on motivation and performance: A regulatory focus perspective. Journal of Organizational Behavior, 32, 1084-1105. doi:10.1002/job.725

Yum, J. O. (2009). The impact of Confucianism on interpersonal relationship and communication patterns in East Asia. Communication Monographs, 55(4), 374-388. doi:10.1080/03637758809376178

Zacher, H., Heusner, S., Schmitz, M., Zwierzanska, M. M., \& Frese, M. (2010). Focus on opportunities as a mediator of the relationships between age, job complexity, and work performance. Journal of Vocational Behavior, 76, 374-386. doi:10.1016/j.jvb.2009.09.001 